\title{
Quantitative analysis of Identification system of country's sustainable development degree
}

\author{
Lei Wang \\ North China Electric Power University, Baoding 071000, China
}

Keywords: Quantitative analysis; the coordination coefficient; clustering analysis.

\begin{abstract}
To consider all the possible parameters connected to the sustainability of a country, divide them into four aspects: Society, Humanity, Resource and Economy. Coordination coefficient is defined by analyzing the mutual influence and restriction between aspects and parameters. The point when coordination coefficient is zero can be roughly recognized as the dividing point of sustainability and unsustainability. For more accuracy, cluster is used to determine the dividing point.
\end{abstract}

\section{Introduction}

Sustainable development has drawn everyone's attention for a long time. Due to the deterioration of the global environment, it satisfies our desire to protect the ecological system, and an increasing number of countries have realized it important to keep sustainable. The concept was defined by The United Nations World Commission on Environment and Development (WCED) in its 1987 report Our Common Future as "Development that meets the needs of the present without compromising the ability of future generations to meet their own needs." However, how to conduct quantitative analysis has been a controversial problem. Different nations have different standards for it, no unified measures have been taken.

So in this paper, an effective model is constructed to discuss the sustainability of a country to create a more sustainable world.

\section{Parameters and Aspects of sustainable development system}

To measure the sustainability of a country, we should consider all the possible influence factors. Too many parameters need to be considered to obtain sustainable development. Divide them into four aspects to simplify the problem: humanity, economic, society and resource. For each aspect, four representative parameters are chosen to describe it:

\begin{tabular}{|l|l|l|}
\hline $\begin{array}{l}\text { Humanity: } \\
\text { Rural population rate }\end{array}$ & $\begin{array}{l}\text { Economy: } \\
\text { Health expenditure per capita } \\
\text { Public health expenditure } \\
\text { International homicides }\end{array}$ & $\begin{array}{l}\text { GDP per capita } \\
\text { GDP } \\
\text { GDP growth } \\
\text { CPI }(2014100)\end{array}$ \\
\hline $\begin{array}{l}\text { Society: } \\
\text { Death rate (per 1000) }\end{array}$ & $\begin{array}{l}\text { Resource: } \\
\text { Anime among women }\end{array}$ \\
Life expectancy & $\begin{array}{l}\text { Freshwater per capita } \\
\text { Population density }\end{array}$ \\
\hline
\end{tabular}

\section{Model to quantitative Measure the Sustainability of a Country}

To measure the sustainability of a country, coordination coefficient is introduced by describing the relationship between and in different aspects. We regard every aspect as a sub system, each sub system has a goal value. For each sub system, the score decided by Entropy Method can be considered as the development index of the sub system. For different sub systems, we can study the influence of different parameters. After thoughtful derivation, the coordination coefficient can be calculated. 


\subsection{Coordination Coefficient of a Sub System}

Considering the mutual influence between sub systems, we define coordination coefficient of sub systems as follow:

$$
\mathrm{U}_{\mathrm{i}}= \begin{cases}U_{1 i}=\frac{1-e^{k_{i}\left(O_{i}-S_{i}\right)}}{1+e^{k_{i}\left(O_{i}-S_{i}\right)}} & \text { When } S_{i} \text { is positive index } \\ U_{2 i}=\frac{1-e^{k_{2}\left(S_{i}-O_{i}\right)}}{1+e^{k_{2}\left(S_{i}-O_{i}\right)}} & \text { When } S_{i} \text { is inverse index } \\ U_{3 i}=\frac{3-e^{k_{3}\left(S_{i}-O_{i}\right)^{2}}}{1+e^{k_{3}\left(S_{i}-O_{i}\right)^{2}}} & \text { When } S_{i} \text { is moderate index }\end{cases}
$$

Where $O_{i}$ is the target goal of the $i_{t h}$ aspect $U_{i}$ is the coefficient of coordination of the $i_{t h}$ sub system. $k_{1} k_{2}$ And $k_{3}$ are coefficient, Can be assigned as the constant greater than zero, the higher the value, the better the sensitivity.

\subsection{Coordination Coefficient Between Sub Systems}

For this part, we take the influence of parameters from different sub systems as consideration. The influence can be calculated as below:

$$
T_{i}^{p}=\sum_{q=1}^{n} T_{i}^{p q} S_{i}
$$

Where $T_{i}^{p}$ means the influence of the $p_{t h}$ parameter from the $i_{t h}$ sub system, $T_{i}^{p q}$ means the influence between the $p_{t h}$ parameter and $q_{t h}$ parameter.

$$
T_{i}=\sum_{p=1}^{n} \sum_{q=1}^{n} T_{i}^{p q} S_{i}
$$

Where $T_{i}$ means the influence that the $i_{t h}$ sub system has.

$$
C_{i}=\frac{T_{i}}{\sum_{p=1}^{m} \sum_{q=1}^{n} T^{p q}} S_{i}
$$

Where $C_{i}$ means the coordination coefficient between sub systems.

\subsection{The Total Coordination Coefficient}

After working out the coordination coefficient in and between sub systems, we can calculate the total coordination coefficient as below:

$$
C=\sum_{i=1}^{n} k_{i}\left(\alpha U_{i}+\beta C_{i}\right)
$$

Where $\sum_{i=1}^{n} k_{i}=1, \alpha+\beta=1$

Now the sustainability can be measured by coordination coefficient. We can all rank all the countries according to their coordination coefficient.

\section{Calculated Conclusion of the Total Coordination Coefficient}

Based on the model we have built above, we calculate the coordination coefficient between system and the coordination coefficient of a system. The result as follow:

\section{How to Judge a Country's Being Sustainable}

The value of the coordination coefficient is between -1 and 1 . We can judge a country to be sustainable if its coordination coefficient is greater than zero, conversely, if a country's coordination 
coefficient is below zero, it should be regarded as unsustainable. To be more authentic, the model of cluster is built to distinguish sustainable countries from unsustainable countries. It can also be used as a test of coordination coefficient

Table 1: Top 8 sustainable countries

\begin{tabular}{cccccc}
\hline Country Name & Economy & Society & Resource & Humanity & C \\
\hline Norway & 0.160945 & 0.364999 & 0.119265 & 0.413015 & 0.858224 \\
Iceland & 0.082751 & 0.307107 & 0.466751 & 0.192405 & 0.849013 \\
Switzerland & 0.141962 & 0.403166 & 0.09124 & 0.401085 & 0.837453 \\
Japan & 0.205054 & 0.470295 & 0.10817 & 0.229964 & 0.813483 \\
Vietnam & 0.580517 & 0.300319 & 0.070704 & 0.060354 & 0.811893 \\
Sierra Leone & 0.026805 & 0.798543 & 0.082245 & 0.072052 & 0.779645 \\
Guinea & 0.049324 & 0.701909 & 0.114959 & 0.093776 & 0.759968 \\
Luxembourg & 0.172168 & 0.330111 & 0.114509 & 0.326453 & 0.743241 \\
\hline
\end{tabular}

Table 2: Top 10 unsustainable countries

\begin{tabular}{cccccc}
\hline Country Name & Economy & Society & Resource & Humanity & C \\
\hline United Arab & 0.07306 & 0.11972 & 0.03607 & 0.06762 & -0.7035 \\
Jordan & 0.02385 & 0.25695 & 0.00456 & 0.06531 & -0.6493 \\
Oman & 0.03942 & 0.26875 & 0.01703 & 0.05553 & -0.6193 \\
Iraq & 0.04144 & 0.31314 & 0.00691 & 0.03468 & -0.6038 \\
Tunisia & 0.03016 & 0.33424 & 0.01862 & 0.05095 & -0.566 \\
Qatar & 0.13285 & 0.20666 & 0.01227 & 0.08384 & -0.5644 \\
Kuwait & 0.09186 & 0.25471 & 0.0315 & 0.06231 & -0.5596 \\
Timor-Leste & 0.02882 & 0.28944 & 0.06993 & 0.06079 & -0.551 \\
Algeria & 0.02718 & 0.36457 & 0.01446 & 0.05422 & -0.5396 \\
Albania & 0.02925 & 0.32783 & 0.05777 & 0.07643 & -0.5087 \\
\hline
\end{tabular}

\section{Summary}

The defined concept coordination coefficient considers the mutual interdependence, constraints and promotion of all the aspects of a country, can measure the sustainability in a more accurate way.

\section{Reference}

[1] United Nations. The future we want. Resolution adopted by the General Assembly. 66th Session of the General Assembly, 123rd plenary meeting; 2012 July 27. New York: UN; 2012 Sep 11 (Resolution A/RES/66/288) [cited 2013 Jul 23].

[2] Brundtland G H. World Commission on environment and development . Environmental policy and law, 1985, 14(1): 26-30.

[3] Zhenxiang Zeng. The analysis of Coordination and sustainable development[J]. System Engineering Theory and Practice, 2001,03:18-21.

[4] Bell, Simon and Stephen Morse. 2008. Sustainability Indicators: measuring the immeasurable. Earthscan, London. 